\title{
Cotidiano
}

\section{MULHER, MERCADO DE TRABALHO E CONSTRUÇÃO DO NÚCLEO FAMILIAR}

\author{
Cristina Castro de Aguiar (1) \\ Cristiane Silva Esteves (2) \\ Magda Medianeira de Mello (3) \\ Gabriela Weber de Itaquy (4) \\ Felipe Oliveira Iatchac (5) \\ Regina Maria Fernandes Lopes (6)
}

\begin{abstract}
Resumo
A inserção da mulher no mercado de trabalho acarretou mudanças na sua relação com o mundo, gerando readaptações em todas as esferas de sua vida. O que incidiu num significativo crescimento do número de mulheres no mercado de trabalho brasileiro nos últimos anos. Tais evidencias mostram relevância ainda no século XXI sobre a repercussão deste novo paradigma na qualidade de vida das mulheres que iniciam sua trajetória profissional e sua vida familiar. O objetivo visa ressaltar os aspectos mais importantes das relações entre o início da carreira destas trabalhadoras e a construção de seu núcleo familiar. Delinear o perfil das mulheres que trabalham, casam, tem filhos; além de refletir sobre como elas se sentem exercendo estes papéis, tentando esboçar o grau de qualidade de vida destas mulheres. Este artigo mostra uma revisão da bibliografia recente sobre a inserção da mulher no mercado de trabalho. Através dos achados indicam que a mulher encontra dificuldades ao conciliar a família com a profissão, o que muitas vezes lhe gera sofrimento, cansaço e estresse.
\end{abstract}

Palavras-chave: mulher; trabalho; qualidade de vida, núcleo familiar.

\section{Introdução}

A inserção da mulher no mercado de trabalho acarretou mudanças na sua relação com o mundo, gerando readaptações em todas as esferas de sua vida. A necessidade de conciliar vida profissional com vida pessoal tem sido uma árdua tarefa para as mulheres. Sua participação no mundo do trabalho gera novas necessidades e novas dificuldades nos universos familiares, como a licença-maternidade, creches, babás, etc (GLAT, 1994). Tem sido significativo o crescimento do número de mulheres no mercado de trabalho brasileiro nos últimos anos. A taxa de participação feminina, como um todo, entre 1982 e 1997, cresceu 35\%, sendo ainda maior esse crescimento para grupos jovens com maior possibilidade de estudos (PAZELLO, 2006). Observa-se, de acordo com Almeida (2007), Pazzelo (2006) e Bueno (1998) que, ainda hoje, as mulheres sofrem desvantagens para ingressarem neste mercado, bem como para manterem-se. Entretanto, alguns avanços com relação aos seus direitos foram alcançados, tais como: licença-maternidade e direito à amamentação. 
Pensando nesta problemática e na sua relevância ainda no século XXI, pretende-se discorrer sobre a repercussão deste novo paradigma na qualidade de vida das mulheres que iniciam sua trajetória profissional e sua vida familiar. Muitos autores referem o sofrimento das trabalhadoras no que chamam "dupla jornada", sobrecarregando-as, muitas vezes, e gerando conflitos tanto no trabalho quanto com marido e filhos. Além disso, constata-se alta incidência de estresse, gerando problemas psicológicos e físicos (GLAT, 1994).

O presente artigo focará as repercussões na vida das mulheres entre o início da carreira profissional e a construção de seu núcleo familiar. Pretende-se entender o que se passa na vida delas quando trabalham, casam e têm filhos; além de refletir sobre como elas se sentem exercendo estes papéis, com o objetivo de compreender as possíveis repercussões da dupla jornada de trabalho sobre a saúde, esboçando o grau de qualidade de vida destas mulheres. Em outras palavras, objetiva-se compreender a relação entre o desempenho de múltiplos papéis e o bem-estar das mulheres.

A metodologia utilizada foi uma revisão da bibliografia sobre mulher no mercado de trabalho, inserção no mercado de trabalho e a construção do núcleo familiar. O estudo baseou-se em uma revisão a partir de levantamento de artigos no Medline/PubMed, PsycINFO e livros nos últimos anos.

\section{Dados históricos}

A maciça inserção das mulheres no campo do trabalho possibilitou com que houvesse uma redefinição de seus papéis diante da sociedade. O feminino, então, passou a ocupar um novo lugar diante do imaginário social, deixando de ser tão minimizado frente ao masculino (RAGO, 2004). O lugar das mulheres que, anteriormente, era visto como pertencente unicamente à esfera privada, definido pelas relações com a família, passa a ser visto na esfera pública, por princípios do mercado capitalista (ROMANELLI, 2000). A referente participação das mulheres na esfera pública e a conseqüente diferenciação perante o social acarretaram transformações diante das relações familiares que necessitaram se readaptar. As configurações familiares sofreram modificações nas suas organizações, nas divisões de tarefas domésticas e educação dos filhos (SARTI, 1997). De acordo com Romanelli (2000), é por meio desse novo papel feminino que se possibilitaram diferentes representações das mulheres, do mesmo modo, propiciando novas formas de relações entre homens e mulheres, dentro e fora da família.

Gilles (2000) afirma que o trabalho feminino surge na sociedade atual como um modo de realização e autoafirmação, uma exigência individual e identitária. Passando a ser visto como um instrumento de realização pessoal, como uma via de ser sujeito de sua própria existência. A busca pelo lado profissional proporciona identidade própria e valorização, porém não se deve esquecer que a mulher não se desvincula das atividades da vida privada, passando, muitas vezes, a exercer dupla jornada (BUENO, 1998). Questão que, muitas vezes, traz uma constante ambivalência de sentimentos quanto aos variados papéis das mulheres e suas desenvolturas nos mesmos. Conforme Betts (2000), tem se tornado necessário que haja um ponto de equilíbrio entre o trabalho e família, pois caso contrário a boa desenvoltura em um pode causar ônus no outro. De acordo com pesquisas realizadas, Verbrugge (1983) e Rosenfield (1980) detectaram os benefícios trazidos pela atuação de múltiplos papéis, sendo estes relacionados à saúde física e também ao bem-estar psicológico. 
Pode-se entender como qualidade de vida no trabalho um conjunto de fatores, tais como: possibilidades de ascensão funcional, segurança, lazer, retorno financeiro esperado, garantia de desenvolvimento e capacitações pessoais e profissionais. De acordo com Domingos (1997), existem duas possibilidades de qualidade de vida, uma referindo-se a questões objetivas, concretas e quantitativas enquanto outra a noções subjetivas, relacionadas à felicidade e bem-estar. Desse modo ressalta-se a importância de ser analisada a influência do trabalho na qualidade de vida do sujeito, enfatizando na trabalhadora mulher o peso da dupla jornada na sua qualidade de vida. Já Oliveira e Traesel (2008) alegam que deve haver reflexões acerca de como as mulheres conseguem dar conta dos variados papéis assumidos e da busca constante por superação e reconhecimento nos mesmos. Assim, as mulheres vivenciam uma constante ambivalência diante das conciliações entre a satisfação na vida profissional e pessoal, podendo ser demonstrada pelo sofrimento.

\section{Sentimento de culpa e carreira profissional}

A busca pela carreira profissional como um projeto individual acaba indo de encontro à manutenção de funções e valores historicamente atribuídos às mulheres. As motivações para o ingresso no mercado de trabalho são diversas, incluindo o desejo de obter realização profissional, a necessidade de sobrevivência e manutenção da família (CHAGAS, MARQUES E BARROSO, 2005). Dessa maneira, elas acabam sentindo-se "responsáveis e culpadas pelas mudanças e acontecimentos indesejáveis no âmbito de suas relações familiares" (ALMEIDA, 2007, p. 413). Nas mais diversas profissões, a jornada de trabalho pode gerar desequilíbrio mental e falta de tranqüilidade, no momento em que culpam-se por sentirem-se divididas entre o trabalho e a família. De acordo com a referida autora, o papel de mãe "evoca o lar" e as tarefas domésticas, já o papel de trabalhadora "requer o afastamento do lar", seja este afastamento físico ou não, como no caso de mães que trabalham em casa, mas que, mesmo assim, acabam sendo "ausentes" na vida dos filhos.

Existe um excesso de responsabilidades que acaba sobrecarregando-as, gerando ansiedade e culpa. Alguns estudos revelam que esta sensação de culpa se liga ao papel de boa mãe esperado pela sociedade, pela família, pelo marido e, muitas vezes, por elas mesmas. A sensação de culpa é um sentimento que está associado ao papel de boa mãe e das responsabilidades maternas para com o concepto. Esse sentimento encontra forte relação na cultura e no processo de educação e socialização do indivíduo. Em uma pesquisa com trabalhadoras das indústrias do setor coureiro-calçadista e similares de Franca/São Paulo, foi constatado que o conflito permeia as relações da mulher com o trabalho e os deveres com a família, seja pela pouca colaboração dos companheiros ou pela falta de aparatos sociais que garantam a educação e guarda dos filhos no período em que estão no trabalho. Além disso, a culpa liga-se ao fato de, por causa do trabalho, terem que abdicar da função materna sem obterem a promoção desejada ou o retorno financeiro esperado (BUENO, 1998).

Entende-se que essas mulheres sentem-se incapazes de dar a atenção devida tanto em casa quanto no trabalho, o que gera uma sensação de incapacidade, de frustração, culpa e que pode gerar um grau de estresse elevado, prejudicando consideravelmente o bem estar destas trabalhadoras (SPINDOLA E SANTOS, 2003). E é esta identidade de mulher-mãe-trabalhadora na sua dupla jornada de trabalho que contribui para ocasionar uma "fragmentação interior e culpa quase que constantes" (FROTA, 2003, p. 37). 


\section{Discussão}

Partindo da constatação de que a mulher tem dificuldade de conciliar a vida familiar e a profissão, pergunta-se sobre os efeitos disso na construção da sua subjetividade e a conseqüente qualidade de vida enquanto sujeito. $\mathrm{O}$ que se processa no imaginário da mulher inserida na cultura atual diante das exigências e do seu desejo em relação à maternidade, o ser mulher e o mundo do trabalho?

Cabe salientar, que a atualidade nos aponta para um perfil de mulher com tendência ao estresse diante do fracasso em manter o que julga ideal em paralelo com o que lhe é exigido naturalmente, no que diz respeito a sua condição de ser. No entanto, que, em termos históricos, o lugar social das mulheres no mundo sofreu mudanças consideráveis da metade do século XX até o início deste século XXI. Alonso (2008) afirma que a mulher do século XIX tinha sua atuação restrita ao espaço privado do lar, onde, seu lugar de rainha, tinha como função principal o cuidado e a educação dos filhos. Dependia economicamente do homem, a quem estava destinado o espaço público, o poder político e econômico e o sustento da família. Atualmente a realidade social em que vivemos retrata as mulheres ocupando um espaço do trabalho e das decisões, conseguiram lugares na fala e na representatividade, em muitos casos, na independência econômica e autonomia para suas vidas.

Lipovesky (2000), um filósofo francês, atribui a esta mulher "além da mulher do lar" o conceito de 'terceira mulher'. Terceira, para o autor, em relação às duas primeiras: a depreciada e a enaltecida, vigentes em outros momentos da história. A primeira teria vigorado durante um longo período, no qual a dominação do masculino sobre o feminino atribuiu todo o lugar aos homens, enquanto mitos e discursos evocavam a "natureza inferior das mulheres". Os poderes das mulheres eram vistos como misteriosos, maléficos, associados à magia, poderes demoníacos e a quem se destinava a implantação do caos. Estes conceitos encobriam o valor real e simbólico subjacente no ser mulher. Nesta época, eram restringidas no espaço social ocupando lugares secundários, enquanto os homens exerciam funções capazes de proporcionar um reconhecimento social. Apesar deste perfil ter predominado até o século XIX, uma segunda mulher, segundo o referido autor, começa a surgir no final da Idade Média - a mulher enaltecida e idolatrada. Esta segunda vai abrindo caminho para a mulher cantada em verso e prosa e nenhum lugar importante se consagrou para ela na vida política e pública. Seu poder seguiu confinado ao lar no imaginário cultural.

Diante do exposto, Lipovesky (2000) afirma que 'a terceira mulher' surge pela desvitalização do ideal da mulher do lar, com a inclusão do mundo do trabalho, o direito a voto, a liberdade sexual e o controle da natalidade. É, para este autor, uma mulher 'indeterminada', no sentido de uma existência feminina à qual lhe é reconhecida a possibilidade de construir um destino individual. As mulheres estão, assim como os homens, entregues ao imperativo de inventar suas vidas, embora ainda se constate uma desigualdade em relação a emprego, remuneração, funções dentro do âmbito familiar, etc. Segundo o mesmo autor há um reconhecimento de 'um gênero com governo de si'.

Foucault (1979) em seus estudos sobre a história da sexualidade nos situa, referindo que o século XIX cria a "Mãe" figura idealizada, santificada, despida de erotismo e de agressividade. O prazer sexual é separado da reprodução, e fica restrito à mulher vulgar. No século XIX, as madonas estão no centro do ideal. Já, no século XX, o surgimento de métodos anticoncepcionais permitiu separar a sexualidade da procriação e, mais recentemente, as novas tecnologias ampliaram as possibilidades em relação ao desejo de ter filhos. A 
maternidade passou a ser um dos caminhos possíveis na vida de uma mulher, quer dizer, uma escolha. As mudanças criaram impasses e possibilidades. As exigências do mercado de trabalho e o desempenho profissional colocado para as jovens mulheres fazem com que a concretização do desejo de ter um filho seja postergada e, às vezes, inviabilizada. Criam-se novos desafios ao desfecho de conciliar o trabalho, a vida profissional bem como o desejo de ter filhos em concomitância com a família.

\section{Considerações Finais}

Assim, na atualidade, século XXI, abriram-se importantes transformações no lugar da mulher no mundo, no entanto poderíamos nos perguntar, será que a mulher corre o risco de apagar o desejo? Segundo Alonso (2008), as mudanças no imaginário instituíram discursos diferentes sobre a sexualidade, sobre o feminino e o masculino deram origem a subjetividades e sintomas diferentes, tanto na clínica quanto no social, introduziram mudanças na forma e na qual as mulheres têm vivido as passagens do feminino: adolescência, a gravidez e a menopausa. O que significa refletir os conceitos que fundamentam os paradigmas

Deste modo, considerando a cultura atual, pensamos que a mulher segue na luta por transformações inter e intrasujetivas, na busca pelo equilíbrio psíquico, a considerar seus desejos, bem como na inserção social e profissional de acordo com o que acredita. "As categorias e papéis de gênero vão se articulando com os caminhos absolutamente singulares construídos na história e na vida familiar e marcados pelos discursos da cultura" (ALONSO, 2008, p. 18) As possibilidades de autonomia parecem ser saídas viáveis para melhorar a qualidade de vida e diminuir o estresse da mulher do século XXI.

\section{Referências}

ALMEIDA, L. S. de. Mãe, cuidadora e trabalhadora: as múltiplas identidades de mães que trabalham. Rev. Dep. Psicol., UFF, Niterói, v. 19, n.2, dez. 2007.

ALONSO, S. (org) e outros autores. Interlocuções do feminino, na clínica, na teoria, na cultura. São Paulo, Escuta/Instituto Sedes Sapiense. 416 p., 2008.

BETTS, J. A. A mulher e o feminino no mundo do trabalho. In: Jerusalinsk, A; Merlo, A; Giongo, L. (org). O valor simbólico do trabalho e o sujeito contemporâneo. APPOA - Associação Psicanalítica de Porto Alegre - Porto Alegre: Artes e Ofícios, p. 99 - 110, 2000.

BUENO, C. M. L. B. A mulher e a culpa - relações entre o trabalho e a maternidade: um estudo realizado com as trabalhadoras das indústrias do setor coureiro-calçadista e similares de Franca [dissertação]. São Paulo: Faculdade de História, Direito e Serviço Social da Universidade Estadual Paulista, 1998.

CHAGAS, M.I.O.; MARQUES, M.F.C; BARROSO, M.G.T. Mulheres Operárias: Vida Doméstica e Qualidade de Vida. RBPS, 2005. 18 (3): 130-135

DOMINGOS, L.A. Qualidade de vida - Concepções e Representações Sociais. Mestrado e Psicologia Social. PUC-SP, 1997

FOUCALT, M. Historia de La sexualidad. La voluntad de saber. México: Siglo XXI, 1979. 
FROTA, L. M. da. Mães antes do tempo: A construção da identidade em adolescentes de classe média. $110 \mathrm{f}$. Dissertação (Mestrado em Estudos Interdisciplinares de Comunidades e Ecologia Social)-Universidade Federal do Rio de Janeiro - UFRJ, Rio de Janeiro, 2003.

GILLES, L. A terceira mulher: permanência e revolução do feminino. São Paulo: Companhia das Letras, 2000.

GLAT, R. Ser mãe... e a vida continua. Rio de Janeiro: Editora Agir, 2a ${ }^{\text {. ed., }} 1994$.

LIPOVETSKY, G. A terceira mulher. Permanência e revolução do feminino. São Paulo: Companhia das Letras, 2000.

OLIVEIRA, C.; TRAESEL; E. Mulher, trabalho e vida familiar: a conciliação de diferentes papéis na atualidade. Disc. Scientia. Série: Ciências da Saúde, Santa Maria, v. 9, n. 1, 2008.

PAZELLO, E. T. A maternidade afeta o engajamento da mulher no mercado de trabalho?: um estudo utilizando o nascimento de gêmeos como um experimento natural. Estud. Econ., São Paulo, v. 36, n. 3, set. 2006.

RAGO, M. Ser mulher no século XXI ou Carta de Alforria. In: VENTURI, G.; RECAMÁN, M.; OLIVEIRA, S. de. A mulher brasileira nos espaços público e privado. São Paulo: Fundação Perseu Abramo, p. 31-42, 2004.

ROMANELli, G. Autoridade e poder na família. In: CARVALHO, M. do C. B. de (Org.). A família contemporânea em debate. 3 ed. São Paulo: EDUC/Cortez, p.73-88, 2000.

ROSENFIELD, S. Sex differences in depression: Do women always have higher rates? Journal of Health and Social Behavior, 21, 33-42, 1980.

SARTI, C. A. Os filhos dos trabalhadores: quem cuida das crianças? In: Bretas ACP. Trabalho, saúde e gênero: na era da globalização. Goiânia (GO): AB; p. 51-60, 1997.

SPINDOLA, T. e Santos, R.S. Mulher e trabalho - a história de vida de mães trabalhadoras de enfermagem. Revista Latino-Americana Enfermagem, Ribeirão Preto, vol.11, n.5, Set./Out. 2003.

VERBRUGGE, L. M. Multiple roles and physical health of women and men. Journal of Health and Social Behavior, 24(3), 16-30, 1983.

\section{Sobre os Autores:}

1. Cristina Castro de Aguiar: Psicóloga, realizando curso de formação em psicoterapia de orientação psicanalítica de adultos pelo ITI. E-mail: cristina-aguiar@bol.com.br .

2. Cristiane Silva Esteves, Graduada em Psicologia (PUCRS), Mestranda em Psicologia Clínica (PUCRS) no Grupo de Pesquisa Avaliação e Intervenção no Ciclo Vital e Pós-Graduanda em Atendimento Clínico, ênfase em Psicanálise (UFRGS). Email: crissilvaesteves@ gmail.com

3. Magda Medianeira de Mello: Doutora em Psicologia pela UAM. Membro Titular da Sigmund Freud Associação Psicanalítica. Sócia efetiva da SPRGS. E-mail: magdamello@terra.com.br

4. Gabriela Weber de Itaquy: Psicóloga. Pós- graduanda em Atendimento Clínico, ênfase em Psicanálise, pela UFRGS.

5. Felipe Oliveira Iatchac, Graduando em Psicologia (PUCRS), Bolsista de Iniciação Científica PIBIC/CNPq pelo Grupo de Pesquisa Avaliação e Intervenção no Ciclo Vital. 
6. Regina Maria Fernandes Lopes, Psicóloga (PUCRS), Dda. Psicologia (PUCRS), Mestre em Psicologia (PUCRS), Especialista em Avaliação Psicológica (UFRGS), Brasil. Supervisora Núcleo Médico Psicológico. Apoio CAPES. Email: reginamlopes@uol.com.br; regina@nucleomedicopsicologico.com.br.

\section{Como citar este artigo (Formato ISO):}

AGUIAR, C.C.; ESTEVES, C.S.; MELLO, M.M.; ITAQUY, G.W.; IATCHAC, F.O.; LOPES, R.M.F.. Mulher, mercado de trabalho e construção do núcleo familiar. Id on Line Revista de Psicologia, Novembro de 2011, vol.1, n.15, p. 05-11. ISSN 1981-1189. 